\title{
Excentricidades coincidentes: W. Gombrowicz en la Argentina
}

\author{
Alejandro García \\ Universidad de Murcia
}

La decisión del escritor polaco Witold Gombrowicz ${ }^{1}$ de instalarse durante 24 años en la Argentina pudo parecer cuando menos excéntrica. Nacido en 1904, viajó a la Argentina en 1939 a bordo del transatlántico "Chrobry" en su viaje inaugural. Sorpresivamente, en el momento justo del regreso decidió bajarse y quedarse en el país. Allí vivió de manera ininterrumpida hasta 1963, en que regresó finalmente a Europa. Murió en Francia seis años después.

Sin duda la larga estancia en el país austral, tan alejado de los centros de emisión cultural, contribuyó a que el reconocimiento de su obra fuese tardío y fragmentario. Sólo la tenaz confianza del polaco en el valor de su creación le permitió atravesar el desierto sin morir de asfixia en él ${ }^{2}$. Como veremos en las

\footnotetext{
${ }^{1}$ Gombrowicz ha sido uno de los talentos artísticos más creativos y fascinantes en la literatura de este siglo. Su obra recrea un mundo inverosímil y personalísimo a través de un lenguaje igualmente particular. Registró y anticipó, además, percepciones y razonamientos del ser humano actual que en otra vertiente han sido insistentemente tratadas por la fenomenología y el existencialismo. En 1936 escribió Ferdydurke, esa explosiva novela de demoledora fuerza y de género inclasificable. Posteriormente aparecería el resto de su obra con títulos como Transatlántico, El Matrimonio, La Seducción, Cosmos y, sobre todo, el Diario (publicado en dos volúmenes por Alianza Editorial, año 1992).

${ }^{2}$ Desierto es una imagen metafórica derivada en todo caso del propio sentimiento que Gombrowicz expresaba hacia la Argentina: "Salir por fin de este suburbio, de esta antesala, de esta despensa, convertirme no en un escritorzuelo, sino en un fenómeno que tenga su propio sentido y su propia razón de ser. Abrirme paso a través de la mortífera mediocridad de mi medio y comenzar por fin a existir. Mi situación es
} 
próximas páginas, el elitista inteligente y el creador de vanguardia que era Gombrowicz estaba mucho más cerca de la realidad periférica e inmadura de la Argentina (de ese "suburbio europeo") que de los clásicos escenarios de la centralidad cultural.

Entenderlo requiere reconocer los dos aspectos biográficos que confluyen en la personalidad del escritor polaco: su peripecia vital y su trabajo de escritor, ambos en estrecho maridaje (un ejemplo de la unificación de vida y obra nos lo brinda la lectura de su Diario) en el que mezcla experiencia personal y discurso, literatura y vida). Gombrowicz no sólo hacía arte escribiendo, lo hacía también viviendo. Su vida en sí es una calculada obra de creación, es una permanente escultura de sí mismo, pero una escultura gobernada por las obsesiones y certezas, en fin, por la filosofía que da sentido a su otra obra: la de ficción. Esta filosofía, núcleo esencial al que se encadena el mundo literario de Gombrowicz, gravita sobre una categoría esencial en su concepción del mundo: la Inmadurez; categoría íntimamente vinculada a otra que le es obsesiva, la Forma.

Sábato, con su habitual agudeza, ha resumido admirablemente el universo gombrowiano: "Para Gombrowicz el combate del hombre se libra entre dos tendencias, la que busca la Forma y la que la rechaza. La realidad no se deja encerrar totalmente en la forma, no hay pensamiento ni forma que pueda abarcar la existencia entera. La lucha entre estas dos tendencias opuestas no se realiza en un hombre solitario, sino entre los hombres, pues el hombre vive en comunidad... Ese combate es el que eternamente se ha librado entre el espíritu dionisiaco y el apolíneo, siendo la existencia del ser humano como un equilibrio entre ambos. Tampoco creo arriesgado suponer que lo que Gombrowicz llama la Inmadurez no es otra cosa que el espíritu dionisiaco, la potencia oscura que desde abajo, como fuerza inferior, presiona y a menudo rompe la máscara, es decir, la Forma que, la convivencia y la sociedad nos obliga a adoptar. Y así como la Inmadurez es la vida (y por lo tanto la adolescencia, el circo, el absurdo, el romanticismo, la desmesura y lo barroco), la Forma es la Madurez) pero también la fosilización, la retórica y, en definitiva, la muerte" ${ }^{\text {3. }}$

Aplicadas tales concepciones artísticas al terreno de la realidad social, Argentina se muestra para Gombrowicz como el país de la Inmadurez por excelencia. Si

dramática y diría que desesperada; llevo bastante tiempo sugiriendo delicadamente a esas mentes amuebladas con "nombres famosos" que, aun sin fama mundial, se puede significar algo, si se es de verdad e incondicionalmente uno mismo ... " Diario I, p. 161.

${ }^{3}$ Prólogo de E. Sábato (1962) a la edición argentina de Ferdydurke. 
para él la juventud es un valor en sí misma, si la Juventud/Inmadurez/Inferioridad son categorías que conoce y en las que se siente a gusto, sin duda la Argentina de los años 40 era, para su sorpresa, la plasmación en un escenario real de sus ensoñaciones metafísicas y distorsionadas: era "el lugar", era "su lugar". Una idea, siempre repetida en el Diario $^{4}$ y permanente a lo largo de su vida, es que se trata de una sociedad inmadura, repleta de los valores que identifican a lo juvenil, a lo espontáneo, a lo poco hecho. Un atributo de la juventud es la belleza, y Argentina es por encima de todo un país naturalmente bello habitado por gentes bellas. "Lo característico de Argentina es la belleza joven y 'baja', próxima a la tierra, y ésta no la encontraréis en las capas superiores. Aquí sólo el vulgo es distinguido... Aquí la belleza no sólo no es nada anormal, sino que precisamente es la reencarnación de la buena salud y del desarrollo medio, es el triunfo de la materia... Lo mismo que con la belleza física ocurre con la forma: Argentina es un país de forma precoz y fácil... ¿Acaso es una masa que todavía no ha llegado a ser pastel, es algo que sencillamente no tiene forma definitiva?" (Diario I, 129)

$\mathrm{Su}$ juventud histórica sería un elemento de superioridad que permitiría a la Argentina encarar mejor el futuro, en comparación, por ejemplo, con la vieja Europa (un ejemplo sería el éxito norteamericano); "menos lastre, menos peso heredado, menos historia) tradición, costumbres y, por consiguiente, una mayor libertad de movimientos y unas mayores posibilidades de elección". La superioridad sería aplastante si no fuera, jay!, por la extremada feracidad y belleza que hacen que la vida en el país suramericano resulte extremadamente fácil. Y la vida fácil hace que las gentes se desacostumbren del "esfuerzo y de la audacia, del riesgo y de la tenacidad, de las decisiones categóricas, del drama y de la lucha, del extremismo, que es la esfera creadora par excellence; la vida fácil ablanda (¿para qué ser duro?)..., todo se deshace" (Diario II, 170). En fin, la demasía de óptimas condiciones disuelve la tensión vital que todo país necesita para desplegarse y lleva implícita la propia inoperancia; este sería el caso

\footnotetext{
${ }^{4}$ Como es sabido, la obra de Gombrowicz tiene dos vertientes: la creación artística propiamente dicha, como explícito escritor de ficciones, y esa otra integrada por el registro de sus experiencias y percepciones (en la que hay una abundante referencia a la Argentina) recogida en el Diario que escribió entre 1953 y 1961 y que fue publicado por entregas en la revista del exilio polaco Kultura. Sus reflexiones autobiográficas se completan en Peregrinaciones Argentinas y más tardíamente en Testamento, libro surgido de una larga conversación con Dominique de Roux.
} 
argentino $^{5}$ (esto podría recordar, en parte, la tesis central del biologismo ilustrado de Buffon o de De Pauw, al indicar que el "exceso de vida" en el nuevo continente era la causa de su "intrínseca degeneración").

Derivado de la juventud, es decir, del hecho de ser una sociedad reciente y sin historia aparente, surgiría otro problema de orden cultural y sería la necesidad patológica para los argentinos de fabricarse una propia historia, "se ponen entonces a demostrar, por ejemplo, que 'nosotros' necesitamos una historia, porque 'nosotros' sin historia no podemos estar a la altura de otras naciones más históricas, y empieza a fabricarse esta historia a la fuerza; la fabricación de la historia consume cantidades inmensas de tiempo (perdido). Se pondrá a meditar qué es en el fondo la Argentina, qué tipo de argentino se debe de ser, etc.". El proyecto individual se disuelve en un destino colectivo impreciso, el 'yo' se borra en beneficio del 'nosotros'. "Es justamente esa inmadurez la que les impone la palabrita 'nosotros'. Están en fase gregaria, que es la fase de toda América del Sur... Mucho de esto sería aplicable a Polonia y a los polacos "(Diario II, 171 y 259).

La visión de Gombrowicz sobre la Argentina no era nueva ni original; otros antes que él habían anticipado el problema de la inmadurez. El discurso fundacional y legitimador repetido en los mitos más permanentes de lo argentino, tanto en clave constructora como en clave crítica, se ha alimentado de esa convicción que situaba al hombre ocupador del territorio y fundador de civilización en necesidad de alerta y combate ante un escenario geográfico que por su bonanza y generosidad podría debilitar los impulsos éticos y dominadores. Esteban Echeverría había advertido en clave poética hace 150 años ${ }^{6}$ (anticipándose a cierta tendencia de la etología contemporánea) que la fuerza bestial de una naturaleza exuberante podía, y de hecho conseguía, desproveer a hombres provenientes de una "civilización superior" de referentes de discernimiento sobre el bien y el mal. Para él, ¿no significaba sino un gigantesco

\footnotetext{
${ }^{5}$ El "exceso de belleza" en Argentina, tema reiteradamente gombrowiano, llevó a una airada réplica de alguien irritado que escribió en una nota necrológica: "Nos amó, pero no nos quiso. Nos conoció, pero no nos comprendió... ¿Tiene acaso un país la culpa de ser rico? ¿De que sus toros y sus tierras sean feraces? ¿Tiene un país la culpa de que sus jóvenes sean física e intelectualmente inquietantes para un escritor como Gombrowicz? Y, por fin, ¿tienen los escritores la culpa de que un colega recién llegado empiece equivocándose?" O.H.V. "Lo insólito como norma" La Nación, 8 septiembre 1968.

${ }^{6}$ Nos referimos a El Matadero, la emblemática narración de Esteban Echeverría publicada por primera vez en 1839 (aprox.).
} 
retroceso hacia la animalidad biológica el dominio incuestionable de Rosas en la sociedad argentina durante más de dos décadas? En esa dirección, Domingo Sarmiento organizó, más tarde, su visión y diagnosis de la Argentina, en su caso en clave "técnico-progresista", sobre el supuesto inicial de la inmadurez ${ }^{7}$. Según Sarmiento, era prioritario dominar el territorio (y no dejarse ser dominado por él, cosa que había ocurrido con la gauchada), rescatarlo de la inmadurez y madurarlo civilizándolo. Es de sobra conocido el impulso "civilizador" que late en la obra de Sarmiento, un impulso que en esa época (segunda mitad del s. XIX) sintoniza con el paradigma central de la racionalidad industrial triunfante en Occidente, y que para los territorios argentinos se traduce en apertura a la emigración europea, puesta en marcha de un aparato educativo integrador, economía liberal manchesteriana, estímulo de la vida urbana y reactualizacion de un literal platonismo político.

Es arriesgado establecer el éxito o fracaso del proyecto sarmientino, o según categorías gombrowianas la manera en que se saldó el combate entre la Inmadurez y la Forma. Desde luego, en el umbral de 1930 coinciden en Argentina dos fenómenos que señalan el final del "proceso civilizador" y la pervivencia de fuerzas telúricas que no han podido ser sumergidas. En lo político se asiste al fin de la democracia "a la europea" y al inicio de una época en la que el país subterráneo emerge súbitamente en un proceso contradictorio de modernización-tradicionalismo, de mestizaje social y político. En la esfera del pensamiento esos años son fértiles en miradas pesimistas sobre los intentos modernizadores del pasado y en tendencias de conformismo determinista. Martínez Estrada, una de las plumas más vigorosas, ocupa oracularmente la voz del fatalismo telúrico y advierte que el dominio civilizador ha sido un espejismo, que Juventud y Forma están destinadas a habitar un mismo espacio, que América no es Europa ni lo será nunca ${ }^{8}$. Lo que para Martínez Estrada se resuelve en pesimismo cultural, para una nueva hornada de jóvenes argentinos será la evidencia animosa de que la Argentina es joven, mestiza y optimista. Ahí está ya el peronismo llamando a la puerta.

La novedad de la mirada de Gombrowicz radica en su sentido de la globalidad, del cosmopolitismo. Para él, Argentina, al igual que su país, Polonia, forma parte del Territorio de la Inmadurez. Son ambos mundos excéntricos, periféricos y

\footnotetext{
${ }^{7}$ El libro más influyente de Domingo F. Sarmiento ha sido Facundo. Civilización y barbarie, cuya primera edición apareció en 1845.

${ }^{8}$ Cfr. Ezequiel Martínez Estrada Radiografía de la Pampa, primera edición fechada en 1933.
} 
alejados de los núcleos emisores. No hay aquí referencias a latitudes geográficas, sino a las culturas; cultura entendida como experiencia vivida. En su teoría de la Inmadurez hay fronteras no convencionales que separan según nuevos criterios unos ámbitos de otros. Argentina es inmadura debido a su juventud histórica; Polonia lo es porque, rodeada de gigantes, no ha podido desarrollar su "yo". Polonia "esa nación siempre fecundada, nunca fecundante, que ha aportado tan poco a la cultura universal" (Diario II, 220). Argentina "más rica en vacas que en arte" (Diario II, 236); o como les dijo al poco de llegar: "El público argentino por falta de producción propia se alimenta con gran avidez de producción extranjera... Cuando llegué a este país me asusté viendo con qué facilidad la joven América asimila los pecados de la vieja y loca Europa"9. En curiosa sintonía con el nacionalismo popular argentino, aunque en su caso derivado de su elección estética en favor de la juventud como valor, Gombrowicz abunda en la posibilidad de vivir en un mundo propio, pero con autenticidad, y distinto al modelo europeo. En la inmadurez se pueden instalar exitosamente, como una forma nueva, distinta en el devenir histórico, las culturas ajenas a la centralidad: "No perdáis el valioso tiempo persiguiendo a Europa, no la alcanzaréis jamás... En lugar de alcanzar la madurez ajena, tratar más bien de sacar a relucir la inmadurez de Europa" (Diario I, 57). Y esto Gombrowicz lo extiende al continente americano: "Soy especialista en su mayor problema, la inmadurez, y toda mi obra gira en torno suyo" (Diario II, 258).

Consecuente (y complementario) con esa elección metafísica por lo joveninmaduro, Gombrowicz el aristócrata despliega su vivir en Buenos Aires buscando lo sano y nuevo de este país en formación, que él identifica con las clases populares. Su elección vital y concreta se orienta hacia el mundo del subsuelo, a las gentes sencillas. "Soy amigo de la Argentina natural, sencilla, cotidiana, popular. Estoy en guerra con la Argentina superior, ya elaborada, jmal elaborada!" (Diario II, 176). Esta es una confesión que discorda, en ese momento, del discurso europeísta y cultivado común a la Argentina burguesa. Incluyendo en la Argentina burguesa ese amplio arco integrado por la clase política tradicional en su conjunto, por la intelectualidad que habitaba un París imaginario, por las élites del dinero naturalmente, y por sus voceros de los medios de comunicación. Ante ese mundo Gombrowicz vivió como un outsider, ajeno y desconocido.

\footnotetext{
${ }^{9}$ Esta frase corresponde a uno ele los tres artículos "alimentarios" que escribió para el diario La Nación, de Buenos Aires. "El arte y el aburrimiento", La Nación 11-6-1944.
} 
"Me fascinaba en este país lo bajo... Me encantaba la oscuridad de Retiro, para mí esa silenciosa, no confesada juventud del país constituía una vibrante confirmación de mis propios estados de ánimo, y fue por eso que Argentina me sedujo como una melodía o como anuncio de una melodía... Para mí si había algo en Argentina, algo que alcanzaba la plenitud de expresión y podía imponerse como arte, estilo y forma, ese algo se manifestaba solamente en las fases tempranas del desarrollo, en lo joven y nunca en lo adulto" (Diario I, 233). Su interés por la vida subterránea lo llevaba, noche tras noche, a frecuentar esa babel nocturno que se daba cita en el Bajo (Retiro) de Buenos Aires, allí donde concurrían en busca de expansión las gentes suburbiales. Obreros, empleados, tanguistas, camorristas y juerguistas; emigrantes recién llegados y gentes de piel oscura y pelo negro. Era este material humano, precisamente, el que Juan Perón, en otros ámbitos, se estaba "trabajando" para su propio provecho, para catapultarse en su carrera política.

Gombrowicz a través de la mirada inocente del meteco pudo quizá percatarse, o cuando menos ser testigo, de lo que otros no veían porque no querían ver, los cambios fundamentales que se estaban operando en la Argentina de los años 40: la emergencia de las clases populares desde las catacumbas hasta el primer plano de la actualidad pública y la posterior, pero muy rápida, entronización en la centralidad nacional de una cultura de raíces proletarias. Los cambios eran consecuencia de transformaciones profundas que habían afectado al tejido social y a la misma experiencia humana de las mayorías y que para sorpresa de algunos se hicieron patentes cuando Perón hizo saltar las aldabas de las compuertas que los encerraban. La meteórica ascensión de Perón acaudillando un nuevo y vasto contingente, el de los ciudadanos hacinados en los ghettos y ajenos a los beneficios de un período, que ahora se clausuraba, de legendaria riqueza, tomó por sorpresa a unas élites eternamente enfrascadas en sí mismas. Como unánimemente recitaba la prensa el 17 de octubre de 1945, ¿de dónde han salido estas gentes de mala pinta?, ¿dónde estaban, en qué madrigueras habitaban que no sabíamos de su existencia? ${ }^{10}$

\footnotetext{
${ }^{10}$ A esta pregunta respondió, al día siguiente, Raúl Scalabrini Ortiz: "Venían de las usinas de Puerto Nuevo, de los talleres de Chacarita y Villa Crespo, de las manufacturas de Vicente López, de las fundiciones y acerías del Riachuelo, de las hilanderías de Barracas. Brotaban de los pantanos de Gerli y Avellaneda o descendían de las Lomas de Zamora. Hermanados en el mismo grito y en la misma fe iban el peón de campo de Cañuelas y el tornero de precisión, el fundidor, mecánico de automóviles, la hilandera y el peón. Era el subsuelo de la patria sublevado". Cfr. Crisis no 31, noviembre 1975.
} 
Gombrowicz no explicitó jamás la opinión que le mereció el peronismo. Sin duda, una vez en el poder le debió de parecer un camelo, además de acabar resultándole asfixiante. Interesa en todo caso reseñar que el peronismo, como fenomenología histórica, se nutre de (y expresa) valores que Gombrowicz había definido desde la literatura como atributos de lo joven-inmaduro. Conviene señalar también que la percepción que ha acabado por imponerse en los profesionales de la historia y de la politología en relación al peronismo es la que coincide con Gombrowicz y lo explica como expresión de inmadurez. El marco de interpretación dibujado inicialmente por el sociólogo G. Germani explicando al peronismo como una respuesta conservadora y temerosa, pero también vital y juvenil a un profundo proceso de modernización se ha dado por bueno.

Otro aspecto de Gombrowicz que merece comentario es el de su escasa relación con los ambientes de la Argentina ilustrada y literaria. Salvo una peculiar amistad con el poeta Mastronardi y con ciertos jovencísimos literatos, el polaco vivió habitualmente "en aislamiento creativo". Justamente las razones que lo acercaban a la Argentina sencilla y autóctona eran las que lo alejaban de los circuitos literarios locales. De nuevo hay que recurrir a su conflicto con la Forma y a su fidelidad a la Inmadurez. El pináculo de la "Argentina culta" en los años 40 estaba ocupado por Borges, la revista Sur y el círculo de la Recoleta. Y con ellos su relación fue eventualmente ácida, pero siempre lejana. "Ellos no estaban enamorados de nada o de nadie y si lo estaban era de Londres, París o Nueva York o, en fin, de un folklore esquemático e inocuo. Pero ninguna chispa auténtica brotaba entre ellos de esa masa oscura de belleza 'inferior"'. El desencuentro, además de las razones derivadas del hermetismo del entorno borgiano o de la también legítima incompatibilidad de caracteres, se debía a diferencias básicas sobre el sentido del arte y de la literatura ${ }^{11}$. Para Gombrowicz, sólo profundizando en lo particular y propio se trasciende hacia lo universal; lo auténticamente íntimo es la vía natural que liga al artista con lo esencial humano y lo convierte en valor clásico para la humanidad. No entendía ni aceptaba la erudición cosmopolita, la especulación estética, la lírica sin vida en fin; supuestos todos ellos que endosaba a la poética de Borges. Igualmente, la frivolidad mundana de los salones literarios cuya sacerdotisa oficiante era la rica Vitoria Ocampo le resultaban inaguantables. La colisión central se situaba en la crítica a "la poca naturalidad" que exhibía la creación artística local, la obsesión por la imitación de lo europeo que entonces (como hoy) la mayoría de los artistas

\footnotetext{
${ }^{11}$ Gombrowicz resumió sumariamente lo que le diferenciaba de Borges: "Borges y yo somos polos opuestos; él se halla enraizado en la literatura, yo en la vida. A decir verdad yo soy antiliterario". Testamento, p. 96.
} 
argentinos eran incapaces de sacudirse de encima. Además, la pose terribilista y antisocial de Gombrowicz resultaba estridente para un grupo que valoraba sobre todo las buenas maneras, la forma y una suerte de melancólica aceptación ${ }^{12}$.

A pesar de sus apreciaciones globales sobre "lo argentino", hay escasísimos comentarios de Gombrowicz sobre la realidad concreta de la Argentina que vivió. No hay referencias a esos 10 años de peronismo del que fue testigo ${ }^{13}$, ni al largo e inestable período que le sucedió, ni se hizo eco de las vastas transformaciones que entre 1940 y 1965 tuvieron lugar y que cambiaron la faz del país. ¿Vivía ajeno a ellas? No es probable si tenemos en cuenta que el sentido último de sus preocupaciones filosóficas y artísticas no fue otro que la liberación del ser humano de las ataduras que lo encadenaban a la Forma y lo convertían en autómata. Simplemente, Gombrowicz no quiso perder su precioso tiempo ocupándose de lo que creía que era la expresión más banal de la Forma, es decir, lo político. Esa actitud en una época impregnada de mitología politicista tenía un nombre: actitud reaccionaria; él lo sabía y comentó brevemente a modo de disculpa: "Mi modo de escribir privado, personal, por ser apolítico, resultó perjudicial para la política"14.

Quiero destacar, sin embargo, de sus comentarios argentinos dos referencias concretas a otros dos aspectos de la política nacional, que derrochan lucidez. Uno es una visión certera, otro es una sospecha premonitoria. En un artículo de 1960 titulado "Demagogia en apuros o un breve reportaje de la Argentina", aprovecha el comentario sobre una huelga general contra Frondizi en 1959 para pasar revista a la lógica de la maquinaria política y de paso fijar su punto de vista. El texto es un brevísimo tratado sobre las fidelidades políticas de la ciudadanía y la poca consistencia de las aferencias colectivas. Puede ser visto como un miniensayo sobre la manipulación de las conciencias y la falta de criterios de hondura en las decisiones, además de una fina mirada al enloquecido y cínico discurso político de la Argentina posperonista. Se trata de un memorable escrito que anticipa la inevitable caída de Frondizi, pleno de sentido del humor, pero de

\footnotetext{
${ }^{12}$ Con un "no nos comprendió" dicho muchos años después por S. Ocampo se resumiría la historia de un desencuentro. Diario Íntimo, p. 59.

${ }^{13}$ Una única referencia al peronismo al hacer balance del año 1955: "(1955) año importante y dichoso, se convirtió en la liberación del... peronismo" Rita Gombrowicz, Diario Íntimo, p. 164, Madrid, 1987.

${ }^{14}$ Declaraciones recogidas en la entrevista "Reside en Buenos Aires un renombrado escritor polaco" en La Prensa, 20 de julio 1962.
} 
un costumbrismo y sentido antropológico desarmante que nos da la pista sobre la opinión que le merecía el hombre argentino en tanto que "ser político".

La segunda y más sorprendente referencia trata de la compleja relación que Gombrowicz mantuvo, entre 1959 y 1963, con Roberto Santucho, creador años después del ERP (guerrilla marxista) y muerto por el ejército en 1976. Tanto en el Diario, como en sus escritos para la radio polaca ${ }^{15}$, como en su correspondencia hay interesantes detalles sobre las conversaciones con Santucho. ¿Qué podía unir a un joven comunista lleno de "entusiasmo, fe en el progreso, idealismo, fe en el pueblo, romanticismo, socialismo, patria" con un viejo escéptico que despellejaba a los comunistas que, según él, habían destrozado a Polonia? Lo que les permitía entenderse era la esencial utilización común de un lenguaje que se refería al rechazo a la importación de lo europeo, al despliegue de las autenticidades, a la necesariedad de ser "yo" sin ruborizarse; en definitiva, a desarrollar y profundizar en la Inmadurez huyendo de la decrepitud importada. Gombrowicz, que políticamente no tomaba en serio a Santucho, apreció en él una fuerza, una autenticidad y una decisión que contrastaban con la politiquería y el eterno discursear de los políticos argentinos, tanto conservadores como revolucionarios: "Es un soldado nato, hecho para el fusil, la trinchera, el caballo" (Diario II, 254). Al mismo tiempo, fue capaz de intuir la posibilidad de un futuro de plomo si personajes como Santucho lograban incubar en condiciones favorables. Un temor premonitorio a que banalidades sin importancia, como serían las ideas políticas, llegaran a convocar a multitudes en una guerra enloquecida, cosa que desgraciadamente ocurriría 10 años después. Fue certero Gombrowicz cuando confesaba sus temores sobre Santucho: "Una mano dispuesta a matar en nombre de una niñería. La prolongación de la patochada que se estaba incubando en su cabeza era una bayoneta ensangrentada. Una criatura extraña, de cabeza confusa, de mano peligrosa" (Diario II, 258).

P.S.

Para responder a la frase con la que abríamos estos comentarios, ¿son suficientes las respuestas de Gombrowicz?:

\footnotetext{
${ }^{15}$ Se trata de 25 artículos cortos dedicados a otros tantos temas relativos a Argentina. Están publicados bajo el título Peregrinaciones argentinas, Madrid, 1987.
} 
"Creo sinceramente que soy entre los escritores extranjeros el que más ha sido fascinado por la Argentina y mi permanencia tan larga aquí no es casual. Pero es una fascinación difícil y quién sabe si no dramática" (Buenos Aires, 1962).

"Con Argentina no puedo romper"(Francia, 1966).

Recibido: 4 de febrero de 2021 Aceptado: 15 de febrero de 2021

Alejandro García estudió en la Universidad de Barcelona y actualmente es profesor de Historia en la Universidad de Murcia. Ha sido profesor visitante en universidades de Francia, México, Colombia, Argentina, Costa Rica y ha llevado a cabo investigaciones en la Sierra Tarahumara y la Frontera Norte (México), Buenos Aires, Magdalena Medio (Colombia), Argelia, Mauritania y Sáhara Occidental, entre otros lugares. Entre sus publicaciones destacan Hijos de la violencia. Campesinos en Colombia sobreviven a golpes de paz (1996), Historias del Sáhara. El mejor y el peor de los mundos (2001) y Los crímenes de Estado y su gestión (2009). alexg@um.es 